\title{
The Economic Independence of Younger Generations and Influential Factors
}

\author{
[ Hyunseo Kim, Jimin Sun, Seoyoung Ko ]
}

\begin{abstract}
The aim of this study was to investigate the state of economic independence of Korean adolescents and young adults, and to explore potential factors that affect their independence. We surveyed 221 high school students on their economic independence and potential influencing factors (e.g. demographics, family relationships, economic satisfaction, etc.). The states of economic independence were divided into four stages; Stage 1 (strong), Stage 2 (average), Stage 3 (weak), and Stage 4 (very weak). We also analyzed big data from 116,797 young adults on their economic activity, based on a population survey provided by the Korea National Statistical Office. Among 221 survey respondents, $33.0 \%$ were classified as Stage $1,22.6 \%$ as Stage $2,29.9 \%$ as Stage 3 , and $14.5 \%$ as Stage 4 of economic independence. Gender and age were statistically significant characteristics that relate to economic independence $(\mathbf{P}<\mathbf{0 . 0 5})$. The most common reason that students wanted to become economically independent was that they did not want to burden their families $(57 \%)$. The data on the economic activity of young adults showed that long-term unemployment rates were higher for females and for younger ages than for other groups. Gender and age were factors that influenced both the economic independence of high school students and economic activity of young adults. Having a stronger will to become independent from an earlier age may have a positive effect on the economic activity of young adults.
\end{abstract}

Keywords-Economic independence, Adolescent, Youth, Family

\section{Introduction}

Recently, a new social phenomenon emerged in societies worldwide. A high proportion of young adults started to become economically dependent on their families regardless of their ability to earn money. In response to this phenomenon, terms such as 'twixter' in the United states, 'kippers' in the United Kingdom, 'boomerang kids' in Canada, and 'kangaroo people' in Korea, were newly coined. According to a survey by ForbesWoman and National Endowment for Financial Education (NEFE), 59\% of parents were found to provide economic support for their children who had finished school. Also, data from OECD showed that $15 \%$ of all youths around the world, roughly 40 million people, were NEET (Not in Education, Employment, or Training). Among NEET youth, $48.6 \%$ were found to be living together with their parents. Furthermore, the emergence of such a phenomenon is reflected as a serious problem in many nations including Greece, Spain, Germany, and the United States.

Hyunseo Kim, Jimin Sun, Seoyoung Ko

Hankuk Academy of Foreign Studies

Republic of Korea
The purpose of this research lies on analyzing the economically independent tendency of the younger generation. As young people become more economically dependent, they tend to spend less money, spending money only on essential goods. This reduces active economic participation, thereby increasing the potential for economic stagnation. Considering that not every society provides support for stable lives after retirement, the economically dependent generation is likely to threaten the upper generation's preparation for retired lives. In addition, the excessive dependence of young adults on their parents reduces their active participation in the labor market and restricts opportunities for skill accumulation, weakening national competitiveness. In brief, both younger and older generations will not be given enough time and opportunities to prepare for their future and life after retirement.

While existing research on this phenomenon focus mainly on economically dependent adults and involve criticisms of their economic incapability, this research approaches the phenomenon from a different perspective. By providing a thorough explanation of the tendency of adolescents, this paper aims to promote a comprehensive understanding of the social problem by comparing existing researches and the results of newly conducted surveys. This paper further hopes to construct firmer economic foundation to help youths gain economic independence and stability, and to suggest efficient solutions to employment problems. Finally, it is expected to encourage deeper social understanding of the phenomenon and to bring about positive influences to society.

\section{Methods}

\section{A. Survey on the Economic Independence of High School Students}

We surveyed from $10^{\text {th }}$ to $12^{\text {th }}$ graders (age 16 19 years) in high school, using both online and offline questionnaires, for the following items: gender, age, sibling relationships, family members with whom they live together, parents' economic activity, age difference with parents, time spent together with their families, economic satisfaction, family satisfaction, friend relationships, and economic independence. Concerning the item of economic independence, respondents were classified into four groups; Stage 1 (strong), Stage 2 (average), Stage 3 (weak), and Stage 4 (very weak). Those who responded that they wanted to achieve economic independence as they entered college, as they married, as they moved out of their parents' house, or did not want to become economically independent were assigned to the four groups regarding the degree of economic independence, respectively. Data collection was 
Proc. of The Sixth Intl. Conf. On Advances In Economics, Social Science and Human Behaviour Study - ESSHBS 2017 Copyright (C) Institute of Research Engineers and Doctors, USA .All rights reserved. ISBN: 978-1-63248-120-7 doi: 10.15224/ 978-1-63248-120-7-71

conducted from June to October, 2016, and a total of 221 responses were received.

\section{B. Analysis of Big data on the Economic Activity of Young Adults in Korea}

We analyzed big data from the Korea National Statistical Office (http://kostat.go.kr), which was centered on the percentage of the economically active population and longterm unemployment rate in Korea. The research gathered national survey data from 116,797 young adults of both genders, from ages 15 19. Data was collected from the years 2004 to 2015 for twelve years.

\section{Statistical Analysis}

Descriptive statistics were presented as frequencies and proportion distribution for categorical variables, whereas continuous variables were expressed as means and standard deviations. Comparisons between groups were made using the chi-square test, Fisher's exact test, Kruskal-Wallis test, and Post-hoc analysis. Analysis for correlation between the independent variable (economic independence) and dependent variables were conducted using Spearman's correlation analysis. All statistical analyses were performed using SPSS ver. 22.0 and Microsoft Excel ver. 2007. Pvalues less than 0.05 were considered statistically significant.

\section{Results}

\section{A. Economic Independence of High School Students}

The characteristics of study subjects and degree of independence are shown in Table 1 and Figure 1.

TABLE I. CHARACTERISTICS OF STUDY SUBJECTS AND DEGREE OF INDEPENDENCE

\begin{tabular}{|c|c|c|c|c|c|c|c|}
\hline \multirow[t]{2}{*}{ Veristios } & & \multirow{2}{*}{ No. af nutjecs } & \multicolumn{3}{|c|}{ Exonuesic intejeedesct } & \multirow[b]{2}{*}{ ittog: 4} & \multirow[t]{2}{*}{ Pmase } \\
\hline & & & bese 1 & tage 2 & tage & & \\
\hline \multirow[t]{2}{*}{ ander } & $\min$ & $96(43.4 \mathrm{WN}$ & inos & $21 \mathrm{~m}$ & $127 x$ & $56 \mathrm{~s}$ & aOS \\
\hline & Penat & $1255850 \mathrm{ny}$ & 35.45 & 22.18 & $227 x$ & $\sin x$ & \\
\hline \multirow{3}{*}{ Sctool prode } & 100 greste & $\operatorname{tscas} 4 x$ & 2025 & 2525 & $35.4 \times$ & $6 x$ & $\operatorname{anz2}$ \\
\hline & 118 grate & $1256556 \mathrm{Wi}$ & 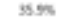 & 1996 & $259 \%$ & $723 \%$ & \\
\hline & 1as grefte & 11 isom & 1825 & $2 x$ & $545 x$ & $\operatorname{ans}$ & \\
\hline \multirow[t]{3}{*}{ Sthing rebtecestips } & Ony diad & 5002604 & 2800 & $360 \%$ & $320 \%$ & s20\% & 0.258 \\
\hline & Citest & $10064522 \mathrm{~W}$ & 35.00 & 220 & $320 \%$ & now & \\
\hline & oter & na2 $\mathrm{nx}$ & $23 \mathrm{ks}$ & $183 \%$ & $25.6 \%$ & $225 \%$ & \\
\hline \multirow{4}{*}{ 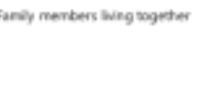 } & Al parens & $105012 \times 4$ & $33 \mathrm{es}$ & $226 \%$ & $363 \%$ & $13.3 \%$ & 2.400 \\
\hline & One parent & 3 [24:4] & בטג & aox & $\omega \pi x$ & 000 & \\
\hline & Crandwerenth & if ary & $\operatorname{axs}$ & $222 \%$ & $167 \%$ & nzwa & \\
\hline & Otwer & $5[2,251$ & opm & $40 \mathrm{~ms}$ & $460 \mathrm{~m}$ & 200\% & \\
\hline \multirow{4}{*}{ Prenta' econerisc activity } & One parentworks & $122 \cos 2 \mathrm{x}$ & $20 \mathrm{~s}$ & $210 x$ & 27.96 & now & $a 140$ \\
\hline & As porents watk & $97,439 \mathrm{~m}$ & ae.1s & $216 x$ & $12.0 \mathrm{x}$ & $\operatorname{ax}$ & \\
\hline & Otwers & $2 n a 9$ & 5003 & ask & sopk & $\operatorname{aos}$ & \\
\hline & Equx or lesu then 20 & $17700 \mathrm{ga}$ & 1145 & $224 x$ & $307 x$ & 140x & axas \\
\hline Age d Alerence wh parefts & More thun 30 peur & Mas ONI & $35 \times$ & 2145 & $286 x$ & $343 \%$ & \\
\hline \multirow[t]{3}{*}{ nime ipentwith tersoy } & Musheme & nactexsy & $20 \mathrm{~s}$ & zsss & $270 x$ & ant & ars \\
\hline & Anerage & $40217 \times$ & 3138 & $16 \pi$ & 436 & $23 \mathrm{~m}$ & \\
\hline & Lens tres & masmen & $400 \mathrm{~s}$ & $227 x$ & $240 \mathrm{cx}$ & $11 \mathrm{x}$ & \\
\hline \multirow[t]{5}{*}{ Lesnaric uraturtion } & Very uatifed & nas $y_{4}$ & anos & $22 \mathrm{x}$ & $20.1 \mathrm{x}$ & noos & ans \\
\hline & Setu/wed & $1006052 z \mathrm{~kg}$ & 2905 & $25 \mathrm{mo}$ & $360 x$ & now & \\
\hline & Amriogs & $99677 \times 4$ & $30 \mathrm{~s}$ & 1796 & $313 x$ & $17 \cdot \boldsymbol{x}$ & \\
\hline & Dsiatsfed & 30200 & $66 \pi$ & $a m$ & 33.36 & ans & \\
\hline & verydesatified & 8 now & opx & $a 0 x$ & $a a k$ & $\operatorname{agn}$ & \\
\hline \multirow[t]{5}{*}{ 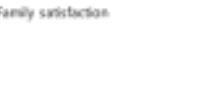 } & Vey sasied & $12466 \mathrm{mWy}$ & 3636 & 23.46 & $266 \mathrm{6}$ & $13.7 \%$ & a916 \\
\hline & Setwled & 3936\% & $265 x$ & $211 \%$ & 3496 & $6 \%$ & \\
\hline & Aumrago & 10 [45:| & $400 \mathrm{~s}$ & 2000 & 9006 & $n \sigma \%$ & \\
\hline & Dhatafited & 3 [10:4 & 3938 & 3336 & $333 \%$ & ans & \\
\hline & Very deasinted & $105 \times 1$ & $1000 \mathrm{~m}$ & aw & aow & ans & \\
\hline \multirow[t]{5}{*}{ 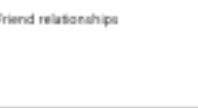 } & Very asated & $1066(4125)$ & 3028 & $21 \pi$ & $302 \mathrm{x}$ & $17 \%$ & ans \\
\hline & Satured & $108(414 \times)$ & 3558 & $23.4 \%$ & 2996 & $112 x$ & \\
\hline & Amrups: & is 1364 & uss & 2506 & $250 x$ & $125 \mathrm{x}$ & \\
\hline & Denatifed & o noxy & om & asx & $\cos$ & $\cos$ & \\
\hline & Foyderatifed & enosi & $00 x$ & aox & $a 0 x$ & $\operatorname{ags}$ & \\
\hline
\end{tabular}

A total of 221 high school students of age 16 to 18 years participated in this study. There were slightly more female students $(56.6 \%)$ than male students $(43.4 \%)$. Of all students,
$88.2 \%$ lived with both of their parents, and $43.9 \%$ responded that their parents both worked. Students who felt that they did not spend much time with their families occupied $33.9 \%$. Most students responded that they were satisfied with their families, economic circumstances, and friend relationships.

As seen in Figure 1A, there were 73 subjects (33.0\%) in Stage 1, 50 (22.6\%) in Stage 2, 66 in Stage 3 (29.9\%), and $32(14.5 \%)$ in Stage 4. It is especially notable that as many as 32 subjects classified as Stage 4 (very weak economic independence) (Figure 1A) responded that they did not want to become economically independent. The most common reasons that students wanted to achieve economic independence were that they did not want to burden their families $(57 \%)$ or wanted to live alone (15\%) (Figure 1B).
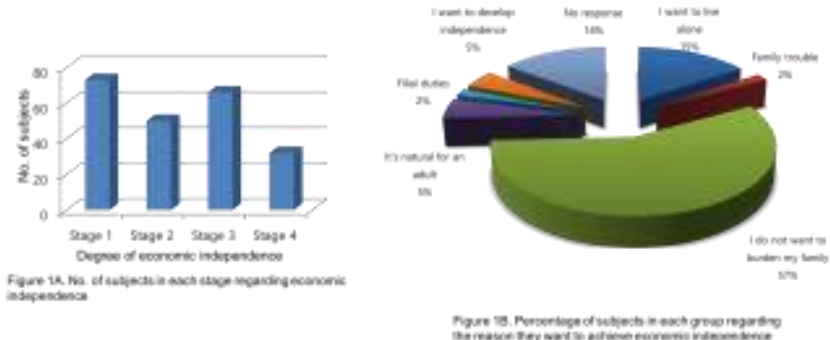

Figure 1. Analysis of survey results on economic independence of high school students

We examined the distribution of economic independence in relation to the characteristics of study subjects, as shown in Figure 2. Gender and age were statistically significant characteristics that relate to economic independence $(\mathrm{P}<0.05)$. Males had stronger economic independence than females, and younger students had a stronger will to achieve economic independence. Students that were extremely unsatisfied with their families tended to show stronger economic independence, and students who spent the least amounts of time with their families wanted to achieve economic independence as soon as possible (Figure 2).

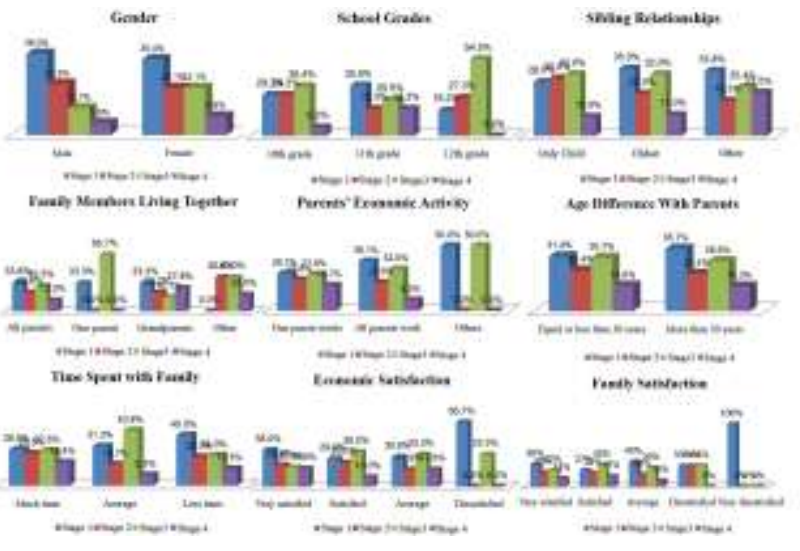

Figure 2. Distribution of economic independence in relation to the characteristics of study subjects

\section{B. Economic Activity of Young Adults in Korea}

According to data from the Korea National Statistical Office, among 116,797 subjects (9,733204 subjects per year), 
$54.3 \%$ were unemployed long-term. The proportion of the economically active population was $7.3 \%$ for ages $15-19$, $52.2 \%$ for $20-24$, and $74.4 \%$ for $25-29$ years, showing an increase along with the age groups. The average long-term unemployment rate was $18.0 \%$, and long-term unemployment was more common among females $(22.1 \%)$ than among males (11.6\%) (Figure 3).
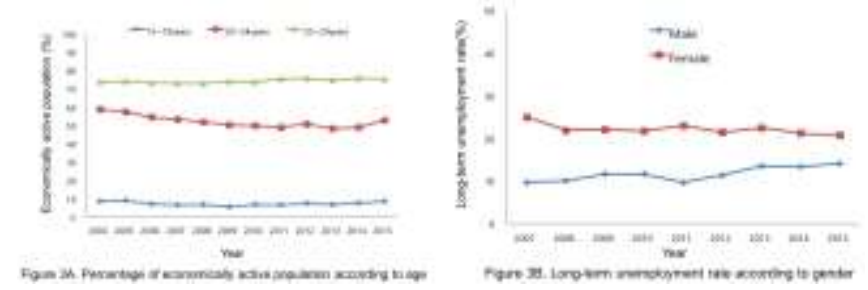

Figure 3. Economic activity of young adults in Korea

\section{Discussion}

This research reflects the most influential factors that determine adolescents' economic independence: age, gender, and family life.

This research shows that adolescents show less tendency for economic independence as they become older. Although various reasons could contribute to this trend, the most likable cause was the discrepancy in perception of society among different ages. It is likely for adolescents to gain more accurate understandings of their society as they become mature. This research fits with previous researches which state that as adolescents grow older, their thinking capacity becomes more complex. Adolescents are more capable of thinking in multiple dimensions, processing information, and understanding oneself and their future (Eccles 1999). Therefore, as adolescents become more mature, they become aware of chronic social problems that force adults to remain economically dependent on their families, which, in turn, discourages their will to become independent. Closer relationships with parents is another factor that contributes to the increasing dependency in accordance with adolescents' age. Adolescents tend to value time spent together with their families more as they get older (Crocetti and Meeus 2014). This phenomenon is relevant not only to adolescents' tendencies but also to those of adults. The gradual process of accepting responsibility for decisions they have made also makes it hard for adults to be wholly independent (Arnett 2005).

Another influential factor is gender. Males were inclined to be more independent than females. Potential reasons behind the difference between the two genders were explained by other studies on gender-associated differences. One study recognized inequalities in social status in relation to gender differences; females were more likely to be hindered by social barriers (Lui et al. 2013). This was also influenced by experiences during adolescence. Girls were more likely to undergo negative experiences due to pubertal development than boys, resulting in lack of confidence (Worell 2001). Traditional gender roles emphasized in society also played a part in the different responses. Assertiveness was not considered an important quality for females, while it was emphasized as an important characteristic that males should have (Eagly and Steffen
1986). Such traditional ideas may still be unconsciously embedded in today's society, influencing adolescent lives.

The family life of adolescents, including family and economic satisfaction, is another main factor that determines their tendency. Adolescents who were not satisfied with their family life wanted to become independent. Family life plays an important role in shaping adolescents' social role and attachment. Existing researches claim that familial affection and association are crucial factors that encourage independence (Spear and Kulbok 2004). Adolescents who grew up in poor home environments were more likely to engage in negative adulthoods. Poor environments were extended to their independent selves after becoming adults (Wickrama et al. 2012). However, this research suggests that adolescents who grew up in poor environments tended to be more independent because they wanted to escape from their circumstances.

Further studies regarding differences in factors such as generations and social contexts should be conducted for more diverse and comprehensive perspectives (Lui et al. 2013). Adolescents' educational levels may be another influential factor that determines their willingness to become economically independent. Additional studies should be conducted to show more direct correlations. Race differences may also provide an alternative perspective in understanding adolescents' tendency.

This research enables comprehensive understanding by analyzing official data provided by a national institution. It thoroughly analyzes a substantial amount of data and compares the results with those of our survey. By doing so, this paper successfully examines the phenomenon by providing analysis of potential influencing factors. The questions were based on constructive reasons and they effectively showed meaningful results. As aforementioned, the data collected were based on a relatively narrow range of questions. Although the questions covered general understandings of subjects' backgrounds and reasons for their responses, they failed to provide answer choices that could effectively account for every reason for their responses about economic independence. Providing survey choices with numerical data would have shown more significant relations among factors. Objective data such as the amount of pocket money subjects receive would have better analyzed the results. Further efforts regarding balanced distribution by extending number of subjects and reducing errors would have improved the research.

\section{References}

[1] Education Database. "Data." Youth inactivity - Youth not in education or employment (NEET) - OECD Data. https://data.oecd.org/youthinac/youth-not-in-education-oremployment-neet.htm.

[2] "Kostat." Kostat.go.kr. http://kostat.go.kr/portal/korea/index.action

[3] Eccles, Jacquelynne S. "The Development of Children Ages 6 to 14." The Future of Children 9, no. 2 (1999): 30. doi:10.2307/1602703.

[4] Crocetti, Elisabetta, and Wim Meeus. "“Family Comes First!" Relationships with family and friends in Italian emerging adults." Journal of Adolescence 37, no. 8 (2014): 1463-473. doi:10.1016/j.adolescence.2014.02.012.

[5] Arnett, J. J. "The Developmental Context of Substance use in Emerging Adulthood." Journal of Drug Issues 35, no. 2 (2005): 23554. doi:10.1177/002204260503500202. 
Proc. of The Sixth Intl. Conf. On Advances In Economics, Social Science and Human Behaviour Study - ESSHBS 2017

Copyright (C) Institute of Research Engineers and Doctors, USA .All rights reserved.

ISBN: 978-1-63248-120-7 doi: 10.15224/ 978-1-63248-120-7-71

[6] Lui, Camillia K., Paul J. Chung, Steven P. Wallace, and Carol S. Aneshensel. "Social Status Attainment During the Transition to Adulthood." Journal of Youth and Adolescence 43, no. 7 (2013): 1134-150. doi:10.1007/s10964-013-0030-6.

[7] Worell, Judith. Encyclopedia of women and gender: sex similarities and differences and the impact of society on gender. San Diego, CA: Academic Press, 2001.

[8] Eagly, Alice H., and Valerie J. Steffen. "Gender and aggressive behavior: A meta-analytic review of the social psychological literature." Psychological Bulletin 100, no. 3 (1986): 309-30. doi:10.1037//0033-2909.100.3.309.

[9] Spear, Hila J., and Pamela Kulbok. "Autonomy and Adolescence: A Concept Analysis." Public Health Nursing 21, no. 2 (2004): 144-52. doi:10.1111/j.0737-1209.2004.021208.x.

[10] Wickrama, K. A. S., Leslie Gordon Simons, and Diana Baltimore. "The Influence of Ethnicity and Adverse Life Experiences During Adolescence on Young Adult Socioeconomic Attainment: The Moderating Role of Education." Journal of Youth and Adolescence 41, no. 11 (2012): 1472-487. doi:10.1007/s10964-012-9764-9. 